\title{
Comunicação \\ Demanda energética por semeadora-adubadora em função da haste sulcadora na semeadura do milho
}

\author{
Carlos Eduardo Angeli Furlani ${ }^{1}$, Ricardo Canova ${ }^{2}$, Fabio Alexandre Cavichioli ${ }^{3}$, \\ Rafael Scabello Bertonha ${ }^{4}$, Rouverson Pereira da Silva ${ }^{5}$
}

\section{RESUMO}

O uso de hastes sulcadoras nas semeadoras-adubadoras de plantio direto tem-se generalizado, principalmente, em áreas de solos argilosos, como alternativa para romper a camada superficial mais compactada. Entretanto, em determinadas condições, a eficiência da haste sulcadora não se mantém, por causa das características relacionadas com o solo, com a semeadura e, até mesmo, com o próprio sistema de preparo. O objetivo deste trabalho foi avaliar o desempenho de hastes sulcadoras, quanto à demanda de energia, em cinco modelos de hastes sulcadoras para semeadora-adubadora no sistema plantio direto. O experimento foi conduzido no campo experimental da empresa Jumil, na cidade de Batatais - SP. Foi utilizada uma semeadora-adubadora da marca Jumil, modelo Guerra JM 7090 EX, com cinco unidades de semeadura. A semeadura do milho foi realizada sobre palhada de braquiária (Urochloa) e foram avaliadas a força e potência na barra de tração, a velocidade de deslocamento, a capacidade de campo operacional e a produtividade da cultura. A produtividade da cultura do milho, a capacidade de campo operacional e a velocidade de deslocamento não apresentaram diferenças para as cinco hastes estudadas e a haste 4, com formato parabólico, apresentou a menor demanda de força de tração e de potência, na barra.

Palavras-chave: máquinas agrícolas, desempenho, plantio direto.

\section{ABSTRACT}

\section{Energy demand of a planter as a function of the furrow opener in corn sowing}

The use of chisel type openers in no-till planters has become widespread, mainly in areas with clay soils, as an alternative to break the most compact superficial layer. However, in some conditions the efficiency of the chisel opener is not constant due to characteristics of the soil, sowing and even the tillage system. Thus, the aim of this study is to evaluate the performance concerning the demand of power from five different chisel openers for a no-till planter. The experiment was conducted in the experimental field of the Jumil Company, in the municipality of Batatais, São Paulo Brazil. A planter fertilizer spreader Guerra JM7090PD EX with five planting units was used in the experiment. Corn sowing was carried out on Brachiaria decumbens Stapf straw The parameters analyzed were force and power in the drawbar, speed, operational field capacity and crop yield. The speed, operational field capacity and crop yield were not significantly among the openers and the opener 4 showed less traction demand and power in the drawbar.

Key words: agricultural machines, performance, no-tillage.

\footnotetext{
Recebido para publicação em 14/03/2012 e aprovado em 24/05/2013

${ }^{1}$ Engenheiro-Agrônomo, Doutor. Departamento de Engenharia Rural, Universidade Estadual Paulista, Via de acesso Professor Paulo Donato Castellane, s/n, 14884-900, Jaboticabal, São Paulo, Brasil. furlani@fcav.unesp.br

${ }^{2}$ Engenheiro-Agrônomo, Mestre. Departamento de Engenharia Rural, Universidade Estadual Paulista, Via de acesso Professor Paulo Donato Castellane, s/n, 14884-900, Jaboticabal, São Paulo, Brasil. ricardo@jumil.com.br

${ }^{3}$ Engenheiro-Agrônomo, Mestre. Departamento de Engenharia Rural, Universidade Estadual Paulista, Via de acesso Professor Paulo Donato Castellane, s/n, 14884-900, Jaboticabal, São Paulo, Brasil. cavichioli2003@ hotmail.com (autor para correspondência).

${ }^{4}$ Engenheiro-Agrônomo, Mestre. Departamento de Engenharia Rural, Universidade Estadual Paulista, Via de acesso Professor Paulo Donato Castellane, s/n, 14884-900, Jaboticabal, São Paulo, Brasil. rafabertonha@ hotmail.com

${ }^{5}$ Engenheiro Agrícola, Doutor. Departamento de Engenharia Rural, Universidade Estadual Paulista, Via de acesso Professor Paulo Donato Castellane, s/n, 14884-900, Jaboticabal, São Paulo, Brasil. rouverson@fcav.unesp.br
} 


\section{INTRODUÇÃO}

A implantação de uma cultura no campo está relacionada com vários fatores, dentre os quais destacam-se: a cultura propriamente dita, a escolha do cultivar, a semente de boa qualidade e vigor, dentre outras, e a máquina que executa a operação de deposição e distribuição das sementes.

Com o uso cada vez maior do sistema plantio direto, as hastes sulcadoras de semeadoras passam a executar, não somente a abertura do sulco para a deposição de semente, mas, também, o preparo do solo localizado na linha de semeadura e a descompactação da camada superficial do solo.

A utilização da cultura do milho, no experimento, explica-se pelo importante papel socioeconômico que desempenha na cadeia produtiva, fornecendo produtos para a alimentação humana e animal e matéria-prima para a indústria.

O estudo de hastes sulcadoras de semeadoras em sistema plantio direto visa a minimizar a demanda de força de tração, promover a mobilização adequada do solo para germinação da semente e emergência da plântula, com consequente melhora na produtividade das culturas. $\mathrm{O}$ simples fato de se aprofundar cada vez mais a haste, para rompimento de camadas compactadas, pode acarretar compactação ainda maior do solo.

Diante disto, torna-se essencial que as semeadorasadubadoras estejam adequadamente dimensionadas e reguladas, especialmente no sistema plantio direto, de modo que as sementes sejam satisfatoriamente distribuídas, em termos de profundidade, posicionamento na linha de semeadura e quantidade necessária, para se obter a população de plantas ideal por unidade de área (Mahl et al., 2004).

$\mathrm{O}$ tipo das hastes sulcadoras e o ângulo de ataque podem promover maior ou menor mobilização do solo, nos sulcos de semeadura, ou seja, mudar a profundidade ou a largura do sulco e, consequentemente, o volume de solo mobilizado, acarretando erosão e exigindo maior ou menor pressão para penetração no solo (Grotta et al., 2009). Outro fator importante a ser analisado é quanto à espessura e à profundidade de trabalho, pois entende-se que, quanto mais larga for a haste sulcadora e maior a profundidade para deposição do adubo, maior serão a força de tração e a remoção de solo (Gamero, 2008).

Na operação de semeadura, devem ser abertos sulcos com largura e profundidade mínimas, de forma a proporcionar economia de potência e, ao mesmo tempo, garantir a adequada deposição do fertilizante e das sementes e o bom desenvolvimento das plantas (Siqueira \& Casão Júnior, 2004).

Os mecanismos sulcadores do tipo haste podem ter diferentes ângulos de ataque para facilitar a penetração no solo, sendo dependentes da transferência do peso da máquina para o trator, proporcionando preparo localizado do solo na linha de semeadura (Casão Júnior et al. 1998).

A força de tração necessária para a operação de semeadoras de precisão, na direção horizontal do deslocamento, já incluída a resistência ao rolamento da máquina, com bom leito de semeadura, varia de $900 \mathrm{~N} \pm 25 \%$, por linha de semeadura (ASAE, 1999).

A exigência de força de tração em semeadoras está relacionada com o tipo de solo, a profundidade de semeadura e adubação, a velocidade de semeadura, o teor de água e o preparo do solo. Nesse sentido, Furlani et al. (2005), trabalhando em sistema plantio direto com semeadora de quatro linhas, espaçadas de $0,90 \mathrm{~m}$, em Latossolo Vermelho eutroférrico (65\% de argila), observaram demanda de força de tração e potência na barra de $20 \mathrm{kN} \mathrm{e} 28$ $\mathrm{kW}$, respectivamente.

Desta forma, os resultados de estudos locais, em diferentes condições de solo e de vegetação, podem auxiliar os fabricantes no aperfeiçoamento de máquinas e, os agricultores, a aperfeiçoarem seu uso, o que, com certeza, contribui para o aumento da produtividade das culturas. Portanto, o objetivo deste trabalho foi avaliar a força de tração e a potência, demandadas por uma semeadoraadubadora, utilizando cinco modelos de hastes sulcadoras, e a produtividade do milho, em sistema plantio direto.

\section{MATERIAL E MÉTODOS}

O trabalho foi conduzido em campo experimental pertencente à empresa Jumil, localizada na cidade de BatataisSP, nas proximidades das coordenadas geodésicas: latitude de $20^{\circ} 53^{\prime}$ sul e longitude $47^{\circ} 35^{\prime}$ oeste, altitude e declividade médias de $862 \mathrm{~m}$ e $4 \%$, respectivamente. O solo da área experimental foi classificado como LATOSSOLO VERMELHO distroférrico (Embrapa, 2006). A cobertura vegetal foi de braquiária (BraquiariadecumbensStapf), que foi dessecada 30 dias antes da semeadura e apresentava, aproximadamente, $6000 \mathrm{kgha}^{-1}$ de matéria seca.

Adotou-se o delineamento experimental em blocos ao acaso, constituído por cinco tratamentos e oito repetições, avaliando-se cinco tipos de hastes (Figura 1). Cada parcela consistiu em uma área de $87,5 \mathrm{~m}^{2}$, sendo $25 \mathrm{~m}$ de comprimento por $3,5 \mathrm{~m}$ de largura. Para mensurar a profundidade de trabalho, realizou-se a retirada do solo mobilizado do sulco aberto pela haste sulcadora e colocouse uma régua com escala em milímetros, na vertical, até a profundidade do adubo, sendo esta de $0,13 \mathrm{~m}$.

As hastes sulcadoras utilizadas no experimento apresentavam largura de $0,0127 \mathrm{~m}$ e diferiram entre si pela forma e pelo ângulo de ataque (ângulo formado entre o fundo do sulco e a soleira da haste, como apresentado na Figura 1, que são: haste 1: reta e $15^{\circ}$, haste 2: reta e $35^{\circ}$, haste 3: reta e $20^{\circ}$, haste 4 : parabólico e $23^{\circ}$, haste 5 : inclinada e $17^{\circ}$. 
Utilizou-se uma semeadora-adubadora da marca Jumil, modelo Guerra JM 7090 EX, pantográfica, equipada para plantio direto, com cinco unidades de semeadura, espaçadas de $0,70 \mathrm{~m}$, entrelinhas, distribuídas em um chassi com largura útil de 3,86 m e sistema dosador de sementes do tipo pneumático. A semeadora-adubadora foi tracionada por um trator New Holand, com tração $4 \times 2$ TDA e potência máxima no motor de 99,3 kW (135 cv) a $2200 \mathrm{rpm}$.

O cálculo da Capacidade de Campo Efetiva foi feito por meio da equação: $\mathrm{CcE}=\left(\left(\mathrm{V}^{*} \mathrm{~L}\right) / 10\right) * 0,65$, Mialhe $(1974)$, em que: CcE: Capacidade de Campo efetiva (ha.h $\left.{ }^{-1}\right)$; V: Velocidade de deslocamento do conjunto $\left(\mathrm{kmh}^{-1}\right)$; L: Largura da faixa de trabalho; $0,65 \mathrm{~m}$ : eficiência de campo.

Para a determinação do teor de água no solo, foram coletadas amostras nas camadas de 0 a 0,1 e 0,1 a $0,2 \mathrm{~m}$ de profundidade, utilizando-se um trado holandês.As amostras foram acondicionadas em sacos plásticos e encaminhadas ao laboratório, para determinação do teor de água, por gravimetria.

A força de tração da semeadora-adubadora foi mensurada, utilizando-se uma célula de carga M. Shimizu, modelo TF400, com escala nominal de 0 a $100 \mathrm{kN}$, localizada entre a barra de tração do trator e o engate do cabeçalho da semeadora-adubadora, cujas informações foram armazenadas em um sistema de aquisição de dados modelo CR23X (Campbell Scientific).A força de tração média na barra correspondeu à média aritmética de todos os valores armazenados, coletados à taxa de aquisição de $1 \mathrm{~s}$. durante o deslocamento do conjunto trator-semeadoraadubadora. Considerou-se, como força de tração pico, o maior valor de força de tração na barra do trator, em cada parcela. A potência média requerida na barra de tração do trator foi determinada pelo produto da força e da velocidade de deslocamento do conjunto trator-semeadoraadubadora, em cada parcela. A velocidade foi monitorada com radar marca Dick John, modelo RVS II, com erro de \pm $3 \%$ para velocidades de 3,2 a 70,8 $\mathrm{km} \mathrm{h}^{-1}$, instalado na lateral do trator, fazendo ângulo de $45^{\circ} \mathrm{com}$ a superfície do solo, e que forneceu valores instantâneos ao sistema de aquisição de dados.

Quantificou-se a produtividade da cultura do milho, colhendo-se as espigas em dez metros na fileira central de cada parcela, no momento em que a cultura atingiu o ponto de maturação fisiológica. Para produtividade, foram amostradas todas as espigas dos dez metros de cada parcela e determinada a massa, expressa em quilogramas por hectare, corrigida para o teor de água de $13 \%$.

O programa estatístico utilizado foi o ESTAT, sendo os dados submetidos à análise de variância pelo teste F de Snedecor, e, quando significativos, as médias foram comparadas pelo teste de Tukey, a 5\% de probabilidade.

\section{RESULTADOS E DISCUSSÃO}

Na Tabela 1, são apresentados os dados de velocidade média de deslocamento, de força média e de força pico na barra de tração, requeridas pelo conjunto trator semeadora-adubadora.

A velocidade de deslocamento não apresentou diferença estatística para os cinco modelos de hastes utilizados, apresentando valores de $6,1 \mathrm{a} 6,4 \mathrm{~km} \mathrm{~h}^{-1}$, próximos à velocidade recomendada para semeadoras-adubadoras com dosador de sementes do tipo pneumático. Ressaltase que a velocidade de deslocamento foi definida em função da potência do trator disponível.

Com relação à força média e à força pico, requeridas na barra de tração para a realização da operação, foram observadas diferenças significativas, entre os tratamentos, com menores valores para a haste modelo 4 (17,53 $\mathrm{kN})$. Essa menor demanda de força está relacionada com a

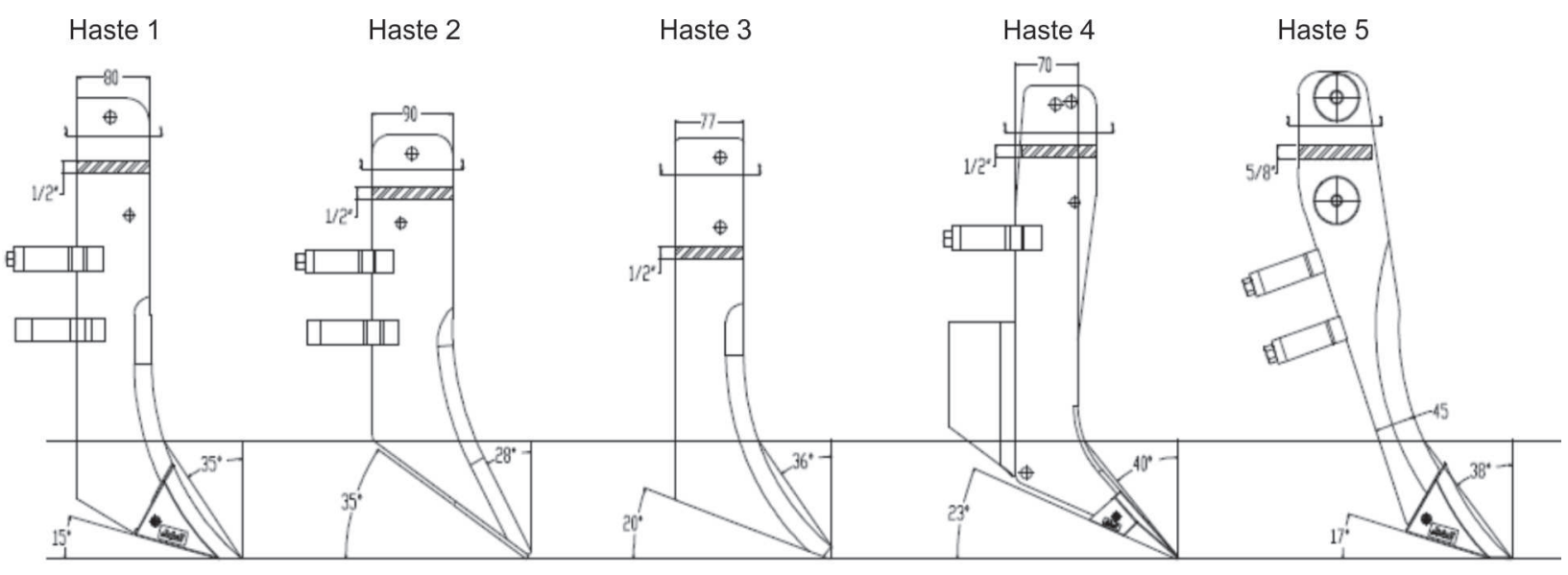

Figura 1. Modelos das hastes sulcadoras utilizadas no experimento. Haste 1: reta e $15^{\circ}$, Haste 2: reta e $35^{\circ}$, Haste 3 : reta e $20^{\circ}$, Haste 4: parabólica e $23^{\circ}$, Haste 5: inclinada e $17^{\circ}$. Todas as hastes atuaram a uma profundidade de $0,13 \mathrm{~m}$ da superfície do solo. 
forma parabólica da haste e com o ângulo de ataque da ponteira. Estas duas características propiciam que a força para romper o solo seja exercida na vertical (para cima), enquanto, nas outras hastes, o rompimento do solo é para a frente, o que resulta em uma maior resistência do solo. Cepik et al. (2010) encontraram demanda de força de tração de $1,3 \mathrm{kN}$ por linha de semeadura, na velocidade de $4,5 \mathrm{~km} \mathrm{ha}^{-1}$, à profundidade de $12 \mathrm{~cm}$. Já Siqueira et al. (2001), utilizando 13 diferentes modelos de sulcadores tipo haste, em semeadoras-adubadoras de precisão, encontraram demandas de força de tração média com valores entre 13,8 e 22,0 kN e profundidade de atuação das hastes de 11,7 a $13,3 \mathrm{~cm}$, respectivamente, trabalhando com velocidade média de $5,5 \mathrm{~km} \mathrm{~h}^{-1}$.

A haste 4, de formato parabólico, apresentou valor de força média demandada na barra de tração de $17,53 \mathrm{kN}$, o que corresponde a 3,50kN linha ${ }^{-1}$. Segundo ASAE (1999), a exigência de força na barra de tração, na operação de semeadura-adubação, varia de 1,10 a 2,00 kN, para solos preparados. O valor encontrado é maior por ter sido a semeadura realizada em sistema plantio direto (solo fir- me). O valor da força de pico é importante para se dimensionar o conjunto trator-semeadora-adubadora. Neste caso, observou-se que o valor dessa força, para a haste modelo 4 , foi menor e próximo dos valores médios das outras hastes.

Na Tabela 2, estão apresentados os valores de potência média e de pico e a capacidade de campo operacional.

A potência é calculada pelo produto da força x velocidade. Como a velocidade não apresentou diferença significativa, as potências média e de pico foram menores para a haste 4 , em relação às potências das demais, fato esse relacionado diretamente com a menor demanda de força de tração da haste 4.

A variação da velocidade de deslocamento não influenciou os parâmetros de força de tração média na barra, profundidade de semeadura e uniformidade de distribuição de sementes; porém, a profundidade de deposição de sementes foi afetada pelos mecanismos sulcadores (Modolo et. al 2004).

Para a variável capacidade de campo, não houve diferença significativa para os cinco modelos de hastes

Tabela 1. Análise de variância expressa pelo teste F e teste de médias para as variáveis velocidades de deslocamento, força média e força pico na barra de tração do trator

\begin{tabular}{lccc}
\hline $\begin{array}{l}\text { Haste } \\
\text { Sulcadora }\end{array}$ & $\begin{array}{c}\text { Velocidade } \\
\left(\mathbf{K m ~ h} \mathbf{~}^{-1}\right)\end{array}$ & $\begin{array}{c}\text { Força }- \text { Média } \\
(\mathbf{k N})\end{array}$ & $\begin{array}{c}\text { Força } \text { Pico } \\
(\mathbf{k N})\end{array}$ \\
\hline 1 & $6,3 \mathrm{a}$ & $19,33 \mathrm{a}$ & $21,61 \mathrm{a}$ \\
2 & $6,2 \mathrm{a}$ & $20,06 \mathrm{a}$ & $22,27 \mathrm{a}$ \\
3 & $6,1 \mathrm{a}$ & $20,42 \mathrm{a}$ & $22,58 \mathrm{a}$ \\
4 & $6,4 \mathrm{a}$ & $17,53 \mathrm{~b}$ & $19,40 \mathrm{~b}$ \\
5 & $6,4 \mathrm{a}$ & $19,35 \mathrm{a}$ & $21,55 \mathrm{a}$ \\
\hline Teste F & $1,55 \mathrm{Ns}$ & $3,61 *$ & $3,39 *$ \\
\hline DMS & 0,5 & 1,82 & 2,9 \\
Média & 6,30 & 19,34 & 21,48 \\
CV $(\%)$ & 5,07 & 8,56 & 8,90
\end{tabular}

Médias seguidas de mesma letra nas colunas não apresentam diferença significativa a $5 \%$ de probabilidade pelo teste de Tukey. $*$ Significativo a $5 \%$ de probabilidade pelo teste de Tukey. ${ }^{\text {NS }}$ Não significativo.

Tabela 2.Potência média e máxima requeridas na barra de tração do conjunto trator e semeadora-adubadora e capacidade de campo operacional, em função dos diferentes tipos de hastes sulcadoras utilizadas

\begin{tabular}{lccc}
\hline Hastes & $\begin{array}{c}\text { Potência-Média } \\
(\mathbf{k W})\end{array}$ & $\begin{array}{c}\text { Potência - Pico } \\
(\mathbf{k W})\end{array}$ & $\begin{array}{c}\text { Capacidade Campo } \\
\left(\mathbf{h h a h}^{-1}\right)\end{array}$ \\
\hline 1 & $33,8 \mathrm{a}$ & $37,8 \mathrm{a}$ & $1,4 \mathrm{a}$ \\
2 & $34,5 \mathrm{a}$ & $38,4 \mathrm{a}$ & $1,4 \mathrm{a}$ \\
3 & $34,6 \mathrm{a}$ & $38,3 \mathrm{a}$ & $1,4 \mathrm{a}$ \\
4 & $31,1 \mathrm{~b}$ & $34,4 \mathrm{~b}$ & $1,5 \mathrm{a}$ \\
\hline & $34,4 \mathrm{a}$ & $38,3 \mathrm{a}$ & $1,44^{\mathrm{NS}}$ \\
\hline Teste F & $1,84^{*}$ & $1,84^{*}$ & 0,3 \\
DMS & 2,7 & 3,1 & 1,4 \\
Média & 33,7 & 37,4 & 5,74 \\
CV $(\%)$ & 8,96 & 9,06 & \\
\hline
\end{tabular}

Médias seguidas de mesma letra nas colunas não apresentam diferença significativa a $5 \%$ de probabilidade pelo teste de Tukey. * Significativo a 5\% de probabilidade pelo teste de Tukey. ${ }^{\text {NS }}$ Não significativo.

Rev. Ceres, Viçosa, v. 60, n.6, p. 885-889, nov/dez, 2013 
sulcadoras avaliados, sendo, em média, de 1,4 hah ${ }^{-1}$. Esse fato está diretamente relacionado com a velocidade de deslocamento, que não apresentou diferença estatística entre os tratamentos, e à largura útil constante da semeadora. Mahl (2006), trabalhando, em solo argiloso, com semeadora-adubadora, encontrou aumentos de 44 e $84 \%$ na capacidade de campo operacional, com incrementos de 2,4 e 2,2 $\mathrm{km} \mathrm{h}^{-1}$, respectivamente, na velocidade de deslocamento da semeadora.

A produtividade do milho poderia ser afetada pela mobilização do solo na linha de semeadura, visto que o desenvolvimento inicial da plântula pode ser dificultado por uma menor mobilização do solo; porém, neste caso, não apresentou diferença estatística para nenhuma das hastes avaliadas (Tabela 3), resultado esse interessante, quando se observa a haste 4 , que exigiu menor força e potência e não alterou a produtividade da cultura, assim, pode-se recomendar esse tipo de haste.

Tabela 3. Produtividade do milho em função dos diferentes tipos de hastes sulcadoras utilizadas

\begin{tabular}{lc}
\hline Hastes & $\begin{array}{c}\text { Produtividade } \\
\left(\mathbf{k g ~ h a}^{-1}\right)\end{array}$ \\
\hline 1 & $11750 \mathrm{a}$ \\
2 & $12507 \mathrm{a}$ \\
3 & $13915 \mathrm{a}$ \\
4 & $11841 \mathrm{a}$ \\
5 & $11291 \mathrm{a}$ \\
\hline Teste F & $2,19^{\mathrm{NS}}$ \\
\hline DMS & 2843 \\
Média & 12261 \\
CV $(\%)$ & 15,91 \\
\hline
\end{tabular}

Médias seguidas de mesma letra nas colunas não apresentam diferença significativa a $5 \%$ de probabilidade pelo teste de Tukey. * Significativo

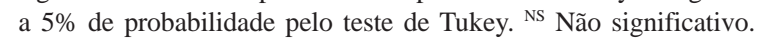

\section{CONCLUSÕES}

A semeadora-adubadora equipada com haste de formato parabólico apresentou menor demanda de força de tração e de potência na barra.

A produtividade de milho, a capacidade de campo operacional e a velocidade de deslocamento não foram influenciadas pelas cinco hastes sulcadoras estudadas.

\section{REFERÊNCIAS}

ASAE - American Society of Agricultural Engineers (1999) Agricultural machinery management. In: ASAE Standards 1999: Standards engineering practices data. Saint Joseph, ASAE. p.359366

Casão Júnior R, Araújo AG, Ralisch R, Silva AL, Ladeira AS, Silva JC, Machado P \& Rossetto R (1998) Avaliação do desempenho da semeadora-adubadora Magnum 2850 PD no basalto paranaense. Londrina, IAPAR. 47p. (Circular, 105).
CEPIK CTC, Trein CL, Levien L \& Conte O (2010) Força de tração e mobilização do solopor hastes sulcadoras de semadorasadubadoras. Revista Brasileira de Engenharia Agrícola e Ambiental, 14:561-566.

Embrapa (2006) Sistema Brasileiro de Classificação de Solos. Rio de Janeiro, Embrapa/CNPSO. 412p.

Furlani CEA, Silva RP \& Lopes A (2005) Avaliação de semeadoraadubadora de precisão trabalhando em três sistemas de preparo do solo. Engenharia Agrícola, 25:458-464.

Gamero AC (2008) Desempenho operacional de um subsolador de hastes com curvatura lateral ("Paraplow"), em função de diferentes velocidades de deslocamento e profundidades de traba1ho. Dissertação de Mestrado. Universidade Estadual Paulista, Botucatu. 72p.

Grotta DCC, Furlani CEA, Silva RP, Lopes A \& Reis GN (2009) Semeadora-Adubadora: Demanda energética em função do manejo da cobertura vegetal e da profundidade da haste de deposição de adubo em sistema plantio direto. Engenharia Agrícola, 26:241-248.

Mahl D, Gamero CA, Benez SH, Furlani CEA \& Silva ARB (2004) Demanda energética e eficiência da distribuição de sementes de milho sob variação de velocidade e condição de solo. Engenharia Agrícola, 24:150-157.

Mahl D (2006) Desempenho operacional de semeadora em função de mecanismos de corte, velocidade e solos, no sistema plantio direto do milho. Tese de Doutorado. Universidade Estadual Paulista, Botucatu. 143p.

Mialhe LG (1974) Manual de mecanização agrícola. São Paulo, Ceres. 301p.

Modolo AJ, Silva SL, Silveira JCM \& Mercante E (2004) Avaliação do desempenho de duas semeadoras-adubadoras de precisão em diferentes velocidades. Engenharia na Agricultura, 12:298306.

Siqueira R, Araújo AG, Casão Júnior R \& Ralisch R (2001) Desempenho energético de semeadoras-adubadoras de plantio direto na implantação da cultura da soja (Glycine Max L.). In: Congresso Brasileiro de Engenharia Agrícola, Foz do Iguaçu. Anais, SBEA. CD-ROM.

Siqueira R \& Casão Júnior R (2004) Trabalhador no cultivo de grãos e oleaginosas: Máquinas para manejo de coberturas e semeadura no sistema de plantio direto. Curitiba, Coleção SENAR. $87 \mathrm{p}$. 